\title{
ANTHROPOMETRIC EVALUATION IN DIABETIC PATIENTS WITH ISCHEMIC STROKE
}

\author{
Maurus Marques de Almeida Holanda', Rosália Gouveia Filizola², \\ Maria José de Carvalho Costa 3 , Emerson Magno Fernandes de Andrade \\ José Alberto Gonçalves da Silva ${ }^{5}$
}

\begin{abstract}
Strokes are one of the most common causes of mortality and long term severe disability. Risk factors for stroke include: age, gender, diabetes mellitus (DM), hypertension, and many others. Objective: To evaluate obesity and hypertension in patients affected by acute ischemic stroke. Method: We compared the anthropometric variables between type II diabetic patients and non-diabetic patients. We evaluated a total of 60 patients, divided into two groups: 34 non-diabetic patients and a group of 26 type II diabetic subjects. Results: The predominance of obesity, as well as hypertension, was very high among the studied groups, presenting no diff e rences among the waist-hip ratio (WHR) values of the study gro up compared to the ones of the control group. Conclusion: The predominance of obesity was very high among the studied groups and there was prevalence the android type obesity. There was no significative difference in the anthropometric evaluation by the measurement of WHR and the waist in the groups.
\end{abstract}

KEY WORDS: st roke, diabetes mellitus, anthropometry, cerebral thromboses, arterial hypertension, risk factors.

\begin{abstract}
Avaliação antropométrica em pacientes diabéticos com acidente vascular cerebral isquêmico
RESUMO - O acidente vascular cerebral (AVC) é uma das causas mais freqüentes de mortalidade e de incapacidade. Os fatores de risco para o AVC incluem idade, gênero, diabetes mellitus (DM), hipertensão art erial e muitos outros. Objetivo: Avaliar obesidade e hipertensão arterial em pacientes diabéticos acometidos por AVC isquêmico (AVC-I) agudo. Método: Comparar as variáveis antropométricas entre pacientes diabéticos (grupo estudo) e não diabéticos (grupo controle). Avaliamos um total de 60 pacientes divididos em dois grupos: 34 pacientes não diabéticos e 26 pacientes com DM tipo 2. Resultados: A prevalência de obesidade foi muito elevada entre os grupos estudados, assim como a hipertensão, não havendo diferença entre os valores da relação abdome-quadril (RAQ) do grupo estudo comparando com a do grupo controle. Conclusão: A prevalência de obesidade foi muito elevada entre os grupos estudados e houve predomínio de obesidade do tipo andróide. Não houve diferença significativa na avaliação antropométrica pela medida da RAQ e da cintura entre os grupos.
\end{abstract}

PALAVRAS-CHAVE: acidente vascular cerebral, diabetes mellitus, antropometria, trombose cerebral, hipertensão arterial, fatores de risco.

St roke is the third leading cause of death in the United States and the main cause of neurological impaiment in adults. Each year, about 500000 Americans suffer from new strokes or from re $c$ u rrences of this disease. According to the American Heart Association Supplement (1997) and Brazilian studies, nearly $25 \%$ of these people die ${ }^{1-3}$. Strokes are one of the most common causes of mortality and long term severe disability. There is an association between higher incidence of stroke and aging. In addition, stroke death rates are typically higher for men than for women and rates for black population are commonly twice as high as those for white. Risk factors for stroke include age, gender, diabetes mellitus (DM), hypertension, impaired glucose tolerance, hyperucemia, smoking, family history of ischemic heart disease (IHD), history of hyperlipidemia, lipoprotein (Lp, total cholesterol, high density lipoprotein cholesterol (HDL), low density lipoprotein cholesterol (LDL), very low density lipoprotein cholesterol (VLDL), triglycerides, apolipoprotein A (apo A) and B100 (apo B100), and many others.

Although stroke continues to be an important cause of death and disability, stroke incidence has

\footnotetext{
${ }^{1}$ M e stre, Neuro ci ru rgião, Hospital Universitário Lauro Wanderley (HULW), Universidade Federal da Paraíba (UFPB), João Pessoa PB, Brasil; ${ }^{2}$ P rofessora Doutora, Endocrinologista, HULW/UFPB; ${ }^{3}$ P rofessora Doutora, Nutricionista, Departamento de Nutrição, UFPB; ${ }^{4}$ Graduando em Medicina, UFPB; ${ }^{5}$ Professor de Neurocirurgia, Neurocirurgião, Hospital Santa Isabel, João Pessoa PB, Brasil.
}

Received 9 May 2005, received in final form 15 September 2005. Accepted 22 October 2005.

Dr. Maurus M.A. Holanda - Rua Santos Coelho Neto 200/802 - 58038-450 João Pessoa PB - Brasil. E-mail: maurus@zaitek.com.br 
been decreasing rapidly in developed countries during the last decades. This is due to the enhancement in control and monitoring of modifiable risk factors ${ }^{2,3}$.

This study aims at evaluating anthropometric measurements as a tool to the diagnosis of obesity, and the association with hypertension, in patients affected by acute ischemic stroke, comparing diabetics with non-diabetics.

\section{METHOD}

This study evaluated patients with ischemic stroke and was undertaken at the Neurological Clinic of Lauro Wanderley University Hospital (HULW), Samaritano and Santa Paula Hospital, located at João Pessoa city, Paraíba State, from November 2000 to January 2002.

We excluded patients with nephro pathy, cholestases, thy roid dysfunction, who take drugs that can increase LDL cholesterd and decrease HDL cholesterol as corticoids, anabolic steroids and progesterone, and smokers, which could modify the factors studied and divert us from the purposes of our investigation.

A total of 60 patients suffering from acute ischemic stroke took part in a case-control study: 26 DM subjects (study group) and 34 non-diabetics (control group). This study intended to evaluate the statistical differences between the two groups.

Both groups were submitted to a nutritional evaluation through anthropometric parameters.

This re se a rch was approved by the Ethical Committee of Federal University of Paraiba. Informed consent was obtained from each subject or subject's parents.

Anthropometric measurement - The anthropometric measu rements investigated were: waist-hip ratio (WHR), waist circumference (WC) and 4 skin folds (mid-triceps, midbiceps, subscapular and supra-iliac).

WHR was calculated as waist circumference (measured midway between the lower rib margin and the superior anterior iliac spine) divided by hip circumference (taken at widest point of the greater trochanters). WHR values exceeding 0.80 in women and 0.95 in men are indicative of increased risk of cardiovascular complications ${ }^{4}$.

The waist circumference is correlated with the abdominal visceral adipose tissue accumulation and values $>102$ $\mathrm{cm}$ in men and $>88 \mathrm{~cm}$ in women, are critical levels, according to NCEP- Adult Treatment Panel III5.

The obesity was classified into two types. The android type shows a dominant visceral and upper thoracic distribution of adipose tissue, whereas in the gynecoid type adipose tissue is found predominantly in the lower part of the body (hips and thighs). Both types of fat distribution are associated with metabolic disturbance and a higher incidence of cardiovascular morbidity and mortality ${ }^{4}$.

High blood pressureis defined as a systolic pressure of $>140 \mathrm{mmHg}$ and a diastolic pressure of $>90 \mathrm{mmHg}^{5}$.

Skinfold thickness was measured at the right side of the body at the biceps, triceps, subscapular, and suprailiac sites using standard calipers (Lange, Cambridge MD, USA) and following standard procedures ${ }^{6}$.

The sites and norms used for skinfolds measurements are:

1. Triceps skinfold: hold the skin and the subcutaneous tissue $1 \mathrm{~cm}$ above the medium point between the edge of the acromial process of the scapula and the olecranon process of ulna. The fold must stand parallel to the biggest axis of the arm. We must be careful and make sure that the measurement is done in the average line of the posterior face and that the arm is relaxed and in the vertical position.

2. Biceps skinfold: lift the cutaneous fold of the arm anterior face, directly above the centre of the cubital fossa, in the same level of the triceps fold and the arm central circumference. The arm must hang relaxed, parallel to the patient body, and the fold ridge must be parallel to the arm axis.

3. Subscapular skinfold: the skin is lifted $1 \mathrm{~cm}$ above the inferior angle of the scapula, the patient arm and shoulder being relaxed. The fold must be parallel to the natural lines of the skin; usually these lines are at $45^{\circ}$ from the horizontal lines that extends themselves medially and cranially.

4. Supra-iliac skinfold: the skin is lifted $2 \mathrm{~cm}$ above the iliac crista in the axillar medium line. The ridge of this fold must stand horizontally.

The measurements of the skinfolds were done in the right half of the body, the limbs standing in an orthostatic position and relaxed. Measurements were done in the left half, when the patient presented with a right motor deficit.

In evaluating the patients, we found that these rates were better than the relation w eight-height or the body mass index (BMI), once most of the patients can not stand in orthostatic position due to the focal motor deficit.

The calculation of the equivalent content of fat, with the percentage of body weight for an age group, was obtained by summing up the four folds previously mentioned, and it was applied to a table according to Durnin and Wonersley ${ }^{7}$, for men and women in different ages. These results were applied to another table of fat percentage for men and women, according to Pollock and WImore ${ }^{8}$, who subdivided them into the following levels: too bad, bad, below the average, average, above the average, good, excellent according to the age.

Katch and McAardle observed than men with more than $20 \%$ of fat body weight and women with more than $30 \%$ are considered obeses ${ }^{9}$, what contributes to the metabolic syndrome and atherogenesis ${ }^{10}$.

Statistical analysis - The statistical analysis used the Statistical Package for Social Sciences (SPSS), version 9.0 for Windows to study the frequency of variables in each group. For the two groups together, the $\chi^{2}$ (qui-square) testwas used. The t-student test was used to compare the average of variables between the study group and the control g roup. The Mann-Whitney test was applied to compare the classification of fat percentage by each group. The probability of significance in all statistical procedures was called $p$, which was compared to the significance level of 0.05 or equal to $5 \%$. 


\section{RESULTS}

Epidemiological data of the groups - This casecontrol study analyzed 60 patients with ischemic stroke. The sample consisted of 26 diabetics ( 15 men and 11 women, whose mean age was $66.35 \pm 9.92$ years old) corresponding to the study group and 34 nondiabetics (22 men and 12 women, whose mean age was $66.71 \pm 10.83$ years old) corresponding to the contrd group. Then, statistical differences were evaluated.

The average age of the patients, considering the study group and the control group, was $66.55 \pm 10.36$ $(X \pm S D)$. The lowest age was 40 years old and the highest was 91 . Half of the patients were below 67 years old; 65 years being the most common age among them.

The levels of arterial pressurewere high in $78.3 \%$ of the patients, considering both groups $(38.3 \%$ in control group and $40 \%$ in the study group).

Anthropometrical index - The averages, the stan$\mathrm{d}$ a rd deviation $(X \pm S D)$ and the minimum and maximal values of WHR and waist in each group are shown in Table 1.

According to the qui-square test, there was not any evidence of association between the WHR and the studied groups $\left(\chi^{2}=1.92 ; p=0.307\right)$, as it can be seen by Table 2 .

The qui-square test was applied to the data from Table 3 and presented a value equal to 0.56 with $p$ value $=0.627$, which shows that there is not an association between abdominal obesity (according to the evaluation of the waist circumference) and the studied groups.

Table 1. Descriptives measures of WHR and waist, and comparison with t-Test for diabetic and non-dia betic control group.

\begin{tabular}{lcccc}
\hline Descriptive measure & \multicolumn{2}{c}{ WHR } & \multicolumn{2}{c}{ Waist } \\
& Control group & Diabetic group & Control group & Diabetic group \\
\hline Average & 0.96 & 0.96 & 93.26 & 97.31 \\
SD & 0.0085 & 0.0073 & 10.34 & 10.83 \\
Minimum & 0.81 & 0.83 & 71 & 72 \\
Maximum & 1.29 & 1.07 & 115 & 114 \\
t-Test & & 0.132 & & 0.895 \\
p-value & 1.470 & & 0.147 \\
\hline
\end{tabular}

Table 2. Distribution of WHR values in type 2 DM patients and control subjects.

\begin{tabular}{lcccccc}
\hline \multirow{2}{*}{ Group } & \multicolumn{7}{c}{ WHR } & & & \\
& $\mathrm{n}$ & $\%$ & $\mathrm{n}$ & $\%$ & & \\
& $\mathrm{n}$ & $\%$ & & & \\
Type 2 DM & 24 & 40.0 & 2 & 3.3 & & \\
Control & 27 & 45.0 & 7 & 11.0 & 1.92 & 0.307 \\
Total & 51 & 85.0 & 9 & 15.0 & & \\
\hline
\end{tabular}

WHR abnormal in men $>0.95$ and in women $>0.80$.

Table 3. Distribution of waist values in type 2 DM patients and control subjects.

\begin{tabular}{|c|c|c|c|c|c|c|}
\hline \multirow{3}{*}{ Group } & \multicolumn{4}{|c|}{ Waist } & \multirow{3}{*}{ Qui-Square } & \multirow{3}{*}{$p$ value } \\
\hline & \multicolumn{2}{|c|}{ Abnormal } & \multicolumn{2}{|c|}{ Normal } & & \\
\hline & $\mathrm{n}$ & $\%$ & $\mathrm{n}$ & $\%$ & & \\
\hline Type 2 DM & 14 & 23.3 & 12 & 20.0 & & \\
\hline Control & 15 & 25.0 & 19 & 31.7 & 0.56 & 0.627 \\
\hline Total & 29 & 48.3 & 31 & 51.7 & & \\
\hline
\end{tabular}


Table 4. Distribution of fat percentage in type 2 DM patients and control subjects.

\begin{tabular}{lcccccccc}
\hline & \multicolumn{9}{c}{ Group } & & & \\
Fat percentage & \multicolumn{1}{c}{ Control } & \multicolumn{2}{c}{ Type 2 DM } & \multicolumn{2}{c}{ Total } & Mann-Whitney & p value \\
& $\mathrm{n}$ & $\%$ & $\mathrm{n}$ & $\%$ & $\mathrm{n}$ & $\%$ & \\
\hline Too bad & 24 & 40.0 & 30 & 50.0 & 54 & 90.0 & \\
Bad & 2 & 3.3 & 2 & 3.3 & 4 & 6.7 & 422 & 0.566 \\
Below the average & 0 & 0.0 & 1 & 1.7 & 1 & 1.7 & \\
Good & 0 & 0.0 & 1 & 1.7 & 1 & 1.7 & \\
Total & 26 & 43.3 & 34 & 56.7 & 60 & 100 & & \\
\hline
\end{tabular}

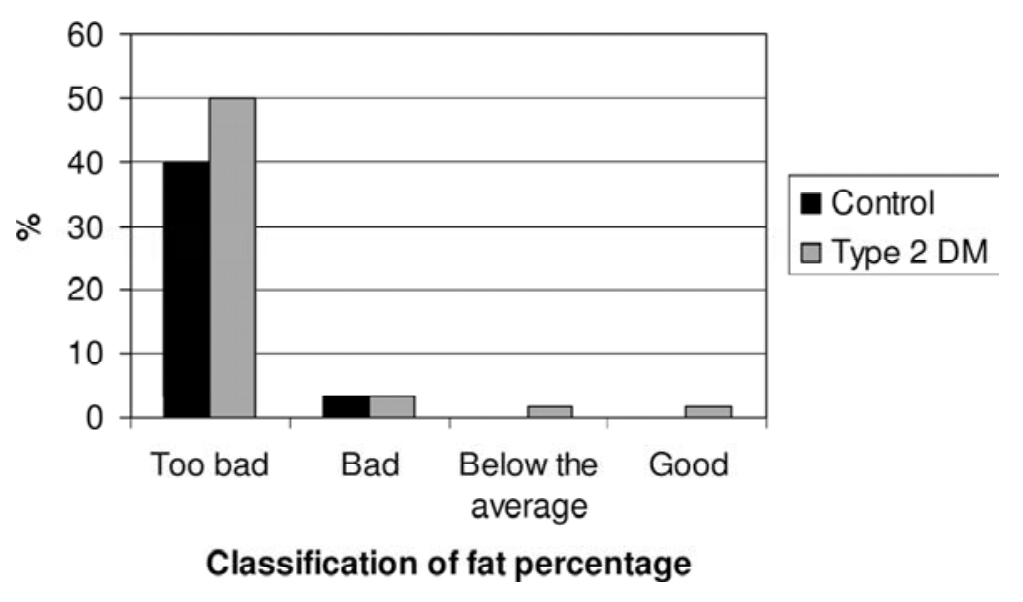

Figure. Classification of fat percentage in type 2 DM patients and control subjects.

We can observe by Table 4 that $90 \%$ of the patients presented a fat percentage in a "very bad" level. From the 26 patients of the control group, $92 \%$ presented a fat percentage in a "very bad" level, and $88 \%$ in the study group.

The Mann-Whitney test was applied (Table 4) in o rder to compare the classification of fat percentage per group, showing no evidence of statistically significative difference between both groups, ( $p>0.566)$. These observations can be seen in Figure.

\section{DISCUSSION}

Groups' characteristics - Sixty patients suffering f rom acute ischemic stroke, being 26 diabetics (study group) and 34 non-diabetics (control group), took part in this study. The Odds Ratio (OR) for sex and gro u $p$ was not significative $(O R=0.744, p>0.05)$, revealing that both, men and women, are susceptible to the same risks of contracting that disease. These results differ from the ones obtained by Pradhan et al. ${ }^{11}$, in which women seem to be susceptible to a higher risk of contracting coronary disease; however, they are similar to the results obtained by Hart et al. ${ }^{12}$, who compared risk factors to stroke in men and women.

Regarding age, we obtained results in accordance to the ones in literature, with averages and standard deviations of $66.55 \pm 10.36$ years old. Diabetes did not have a significative influence in the precocity of stroke, once the average age was similar in both groups. In the casuistry of Broderick et al. ${ }^{3}$, the patients above 55 years old suffe red more than others from stroke attacks.

In the sample, the age of the patients ranged from 40 to 90 years. In the study group, the average and the standard deviation ranged from $66.35 \pm 9.92$ years, and in the control group, from $66.71 \pm 10.83$ years, which is in accordance with established in the literature.

An th ropometric profile - Obesity is a chronic disease that has been increasing significatively worldwide; being one of the main risk factors for the developing of diabetes type 2 and, consequently, ischemic stroke ${ }^{13}$. 
The pattern distribution of body fat and visceral adipose, when altered, can induce to the emergence of both DM and glucose intolerance, being related to ages below 65 years old. The predominance of DM type 2 reaches $16 \%$ in men and $12.8 \%$ in women from 75 to 84 years old. Above 65 years old, the DM and the glucose intolerance reaches $30 \%$ to $40 \%$ in the patients from the Framingham study ${ }^{14}$.

We observed that there was no significative difference between the WHR, the waist circumference and the fat percentage; thus, characterizing a group homogeneity (Table 1).

As to the checking of the cutaneous folds values, in the left or right side of the body, Womersley, Durnin cited by Durnin, Womersley ${ }^{7}$ did not find statistical diffe rences when evaluating the fat percentage using the measures of the cutaneous folds in the right side in comparison to the ones of the left side. On the other hand, studies undertaken by Gwinup, Chelvam and Steinberg ${ }^{15}$, comparing the superior limb of tennis players in activity to the other limb without activity, concluded that there was no significative difference as well.

The study group presented body fat percentage average similar to that of the control group, which was considered above the average in $96.7 \%$ of the cases. It can be observed from Table 4 , that $90 \%$ of the patients presented a fat percentage in a "very bad" level. From $34 \%$ of the control group patients, $92 \%$ of them presented this same level of fat percentage, and the diabetic group, $88 \%$. It is relevant to point out that, among the 60 patients studied, only one individual presented a fat percentage conside red "good" (1.7\%). The waist-hip ratio presented average and standard deviation of $0.96 \pm 0.0085$ in the control group, and $0.96 \pm 0.0073$ in the study $\mathrm{g}$ roup; $85 \%$ of the patients were out of the norm a Iity limit, from these, $40 \%$ belonged to the diabetic group and $45 \%$ to the control group. The abdominal obesity, translated by the waist circumference in the $p$ resence of overweight, is associated to the insulin resistance as well as to the metabolic syndrome, being more correlated to metabolic risk factors than to the isolated increasing of BMI. Therefore, the simple mea$s$ u rement of the abdominal circ u $\mathrm{m} f \mathrm{fe}$ rence is re co $\mathrm{m}$ mended to identify the risk component ${ }^{5}$.

The percentage of male patients, suffering from stroke, that presented an abdominal circumference value higher than $102 \mathrm{~cm}$ was $18.3 \%$, and $30 \%$ of female patients were higher than $88 \mathrm{~cm}$. Comparing women among themselves, it was observed that
$78.3 \%$ of them were out of the limit of abdominal circumference normality, and $29.7 \%$ of the men.

The values of the waist, presented by Table 3, point out the diabetic group, in which the average value is higher than that of the group control, i.e., the average value of the waist of diabetics is $4.3 \%$ higher than the average waist of the control group; although, besides this slight difference, there was no association between obesity (according to the waist circumference evaluation) and the studied groups ( $\chi^{2}$ $=0.56, p=0.627)$. Therefore, the data from the present study of percentage and distribution of body fat can possibly point to the existence of insulin resistance in both studied groups, even if the basal level of insulinemia had not presented a conclusive result regarding such a hypothesis.

The abdominal circumference presented itself as a rate of adiposity better than the other rates, reporting a strong risk factor to health, once it is responsible to the accumulation of abdominal fat. The advantage of this adiposity rate consists in not being influenced by height ${ }^{16}$. This fat distribution in the abdomen seems to be a metabolically active tissue, constantly renewing itself. In addition, in relation to lipolyses, this tissue seems to be more sensitive to catecholamines, which differs from the preservative action of the insulin ${ }^{17}$. These results show a small difference between the two groups, in spite of the fact that the small quantity of obese people in the diabetic group called our attention to the work of Nawawi et al. ${ }^{18}$, which shows the severity in the association of more than one risk factor. The diabetes type 2 and the obesity are associated to atherogenic risk factors ${ }^{19,20}$.

In the literature, there are many studies showing an increase in the metabolic activity of the visceral fat, which would be more responsive to an activation of the hypothalamus-hypophisis-adrenal axis in individuals with a BMI increase ${ }^{5,10}$. Regarding the visceral obesity clinically translated, although not precisely, because of the increase in the WHR, it is been observed an increase in the production of atherogenic lipoproteins, in particular, the LDL. Besides, the increase of free fatty acid can constitute a substract to a higher hepatic production of VLDL, rich in triglycerides ${ }^{21}$. However, the authors of this present research, in a study published and undertaken with the same group of patients, had not found a correlation between the WHR and the fractions of lipoproteins or apoliproteins analyzed, except for the concentration of Lp (a), that was positively correlated to abdominal adiposity, in both groups, using the waist-hip ratio $(p<0.05)$ as a parameter ${ }^{22}$. These findings were 
p reviously re p o rted, and the WHR was considered as a determinant independent of the $\mathrm{Lp}(\mathrm{a})$ concentration, both in patients with DM type 1 and patients with DM type $2^{23,24}$. By the contrary, such a correlation was not found in non-diabetics patients ${ }^{25}$.

A therapeutical objective in the control of the main risk factors of stroke, such as the hypertension, very frequent in both groups, is to find a drug with a good tolerance profile to treat patients with overweight or android obesity, without bringing alterations in the metabolism of carbonate hydrates and lipids 26

$S t$ roke places a tremendous burden on health reso u rces throughout the world. Improved detection and modification of risk factors can reduce the impact of this disease. The strong association between diabetes mellitus and obesity suggests that these factors must be strictly controlled.

In conclusion, the predominance of obesity was veryhigh among the studied groups, and there was a prevalence of the android type obesity, suggesting that there is a possible insulin resistance in the process. There was no significative difference in the anthropometric evaluation by the measurement of WHR and the waist in the groups. Only arterial hypertension was higher in the diabetic patients compared to the non-diabetic ones.

\section{REFERENCES}

1. Lessa I. Epidemiologia das doenças cerebrovasculares no Brasil. Rev Soc Cardiol Estado de São de Paulo 1999;4:509-518.

2. Sacco RL. Risk factors and outcomes for ischemic stroke. Neurology 1995;45:510-514.

3. Broderick JP, Brott T, Tomsick T, Huster G, Miller R. The risk of subaracnoid and intracerebral hemorrages in blacks as compared with whites. N Engl J Med 1992;326:733-736.

4. Fernandes J Filho. A prática da avaliação física: testes, medidas e avaliação física em escolares, atletas e academias de ginástica. Rio de Janeiro: SHAPE, 1999.

5. Executive Sumary of the Third Report to the National Cholesterol Education Program (NCEP) Expert panel on detection evaluation and t reatment of high blood cholesterol in adults (Adult Treatment Panel III), JAMA 2001;285:16-19.

6. Waitzberg DL, Ferrini MT. Exame físico e antropometria. In Waitzberg DL (ed). Nutrição oral, enteral e parenteral na prática clínica, 3.ed. São Paulo: Editora Atheneu 2000:16-17.
7. Durnin JV, Womersley J. Body fat assessed from total bodydensity and its estimation from skinfold thickness: measurements on 481 men and women aged from 16 to 72 years. Br J Nutr 1974;32:77-97.

8. Pollock ML, WilmoreJH. Exercícios na saúde e na doença: avaliação e p rescrição para prevenção e reabilitação. 2.ed. Rio de Janeiro: Medsi 1993:43-45.

9. Katch FI, Mcardle WD. Prediction of body density from simple anthropometric measurements in college-age men and women. Hum Biol 1973;45:445-454

10. Zhu S, Wang Z, Shen W, Heymsfield SB, Heshka S. Percentage body fat ranges associated with metabolic syndrome risk: results based on the third National Health and Nutrition Examination Survey (19881994). Am J Clin Nutr 2003; 78:228-235.

11. Pradhan AD, Skerrett PJ, Mason JE. Obesity, diabetes and coronary risk in woman. J Cardiovasc Risk 2002;9:323-330.

12. Hart CL, Hole DJ, Smith GD. Comparisom of risk factors for stroke incidence and stroke mortality in 20 years of follow-up in man and women in the Renfrew/Paisley study in Scotland. Stroke 2000;31: 1893-1896.

13. SilvestreJA. Hospitalizações SUS 1997. Coordenadoria da Atenção à Saúde do Idoso. Ministério da Saúde.

14. Kannel WB. Fifty years of Framinham Study contributions to understanding hypertension. J Hum Hypertens 2000;14:83-90.

15. Gwinup G, Chelvam R, Steinberg T. Thickness of subcutaneous fat and activity of underlying muscles. Ann Intern Med 1971;74:408-411.

16. Lean MEJ, Han TS, Seidell JC. Impairment of health and quality of life in people with large waist circumference. Lancet 1998;351:853-856.

17. Large V, Arner P. Regulation of lipolysis in humans. Pathophysiological in obesity, diabetes, and hyperlipidaemia. Diabetes Metab 1998;24: 409-418.

18. Nawawi HM, Muhajir M, Kian YC, Mohamud WN, Yusoff K, Khalid BA. Type of diabetes and waist-hip ratio are important determinants of serum lipoprotein (a) levels in diabetic patients. Diabetes Res Clin Pract 2002;56:221-227.

19. Wilson PW, Kannel WB. Obesity, diabetes, and risk of cardiovascular disease in the elderly.Am J Geriatr Cardiol 2002;11:119-123.

20. Bjorntorp P. The origins and consequences of obesity. Diabetes. Ciba Found Symp 1996;201:68-80.

21. Bener A, Zirie M, Al-Rikabi A. Genetics, obesity, and environmental risk factors associated with type 2 diabetes. Croat Med J 2005;46: 302-307.

22. Holanda MM, Filizola RG, Costa MJ, Andrade RV, Silva JA. Plasma li p o p rotein(a) levels: a comparison between diabetic and non-diabetic patients with acute ischemic stroke. Arq Neuropsiquiatr 2004;62: 233-236.

23. Gambhir JK, Kaur H, Gambhir DS, Prabhu KM. Lipoprotein(a) as an independent risk factor for coronary artery disease in patients below 40 years of age. Indian Heart J 2000;52:411-415.

24. Poon M, Zhang X, Dunsky KG. Apoplipoprotein(a) induces monicyte chemotactic activity in human vascular endothelial cells. Circulation 1997;96:2514.

25. Gillum RF. Indices of adipose tissue distribution, apolipoproteins B and AI, lipoprotein (a), and triglyceride concentration in children aged 4-11 years: the Third National Health and Nutrition Examination Survey. J Clin Epidemiol 2001;54:367-375.

26. Kohlmann O Jr, Ribeiro AB. Manidipine in the treatment of stage I and II essential hypertension patients with overweight or android obesity: a Brazilian multicentre study of efficacy, tolerability and metabolic effects. Arq Bras Cardiol 2001;77:463-470. 